\title{
A Study of the Application of Proportionality Principle in Civil Jurisdiction
}

\author{
Feifei Lin \\ Beihua University Law School, no.3999, hua shan road, jilin city, jilin province, China \\ linfeifei_beihua@163.com
}

Keywords: Proportionality Principle; Civil Judicial Discretion; The Rule of Law

\begin{abstract}
The proportionality principle is one of the important principles of administrative law. This concept is slightly abstract. In specific cases, the trade-offs between administrative and administrative purposes, private interests and public interests are all applied to the principle of proportionality. At the level of value, they should be measured by the executive authorities. Therefore, in the application of the proportionality principle in the field of civil justice, judges should control civil judicial discretion within a certain range, increase its percentage, and make it more applicable in the judicial field.

Article 16 of the "Human Rights Declaration" stipulates: "If the state does not protect the rights of the people, it does not adopt a system of separation of powers and it can be regarded as having no constitution." It shows the spirit of modern constitutionalism - a power government that guarantees limited power by safeguarding people's basic rights and decentralization. Modern rule of law countries are based on the spirit of constitutionalism and legally and reasonably restrict the exercise of power. Only with special adjustments based on special circumstances, based on this principle, the "proportional principle" of the law is derived and it becomes the basic principle for the defense of all acts of the modern legal state. However, the proportionality principle introduces jurisdictional power over the control and management of administrative powers in administrative law and gives the court discretion.
\end{abstract}

\section{The Connotation and Status of the Proportionality Principle}

When the reality forms goals and protects the rights of relatives, if the agency adopts the proportionality principle, it will have some negative effects on the rights of relatives, so the two should be restricted in a moderate proportion and try their best to control within a certain range. With respect to the principle of proportionality, different researchers have different opinions and knowledge about their contents. Generally, the principles of sexuality, necessity, and balance are principles of proportionality. ${ }^{1}$

Principle of Appropriateness. Both the principle of suitability or the principle of appropriateness are based on the principle of appropriateness, and the way in which the principle of applicability is pointed out can certainly fulfill administrative purposes, or it can have a positive effect on administrative purposes. Its illegal standard is that the implemented method must be able to achieve administrative purposes. The fact that the method implemented by the executive authorities can achieve the appropriate principle is the intended purpose of the legislator.

The Principle of Necessity. The principle of minimum infringement also refers to the principle of necessity, and it supplements the principle of appropriateness. Based on the principle of appropriateness, if the correctness of means and purpose is judged to be the principle of appropriateness, the principle of necessity is inferred to be true just as the purpose of the way. This principle basically requires that the administrative subjects have several different administrative behaviors or multiple administrative methods to choose from on the way to the public interest, so that the choice of such methods and behaviors by administrative subjects must be necessary. The request should satisfy the minimum degree of infringement on civil rights.

Narrower Proportionality Principle. This principle is also known by some scholars as the "equilibrium principle", which means that there is a proper balance between the rights of the infringed citizens and the expected public value of the administrative acts adopted by the 
administrative subjects. The proportion of damage caused by equity should be larger, at least equal. This is also the same with the use of the way and the expectations reached should be within a certain range of changes, does not meet the principle of the connotation of the situation for the administrative behavior of relatively large damage to personal interests to gain a smaller public interest. The imbalance between the way and the expected ratio achieved is similar to the chicken killing and egg retrieval in ancient China.

\section{The Function of the Proportionality Principle - Supervising Administrative Discretion at Judicial Discretion}

The proportionality principle is abstract rather than concrete, and its concept is also somewhat ambiguous. The proportionality principle emphasizes a certain balance between means and purpose, and the proportionality principle is to use "means and purposes" as the key guidance and strictly control. When the purpose is achieved in an inappropriate way, this situation is not allowed in the principle of proportionality. On the one hand, through the measurement of interest and the judgment of value, civil judicial supervision over administrative power also invokes civil judicial discretion. At the same time, applying to specific cases involves the trade-offs between administrative measures and administrative purposes, and between private interests and public interests. In summary, through the principle of proportionality, the discretion of civil jurisdiction plays a supervisory role in administrative power.

Civil Justice Judicial Entrance. In the traditional concept of justice, almost all judges do not support value judgments. As a result, judges are forced to accept laws and regulations so that judges cannot make value judgments or measure profits when necessary. Aristotle proposed that when it comes to making laws, its standard should be "as few outstanding issues as possible for judges to resolve." "Ethical and political aspects, if legislators let the court make up for it, it is almost equivalent to The judge replaced the legislator. In this way, the power of the court is enormous. Kelsen said. However, in the real life, the legal system must be flawed and incomplete in the process of formulation and implementation. However, the above point of view requires perfect and flawless idealism. In the judgment process, logical reasoning based on the existing legal norms, not all decisions are satisfactory. This proves the importance of judiciary discretion and provides judges with necessary value judgments in judicial activities and provides objective preconditions and confirmation. The proportionality principle is derived from administrative law under this theoretical principle, and the content of this principle is abstract, and the fact is that the judge receives a blank form of commission from the legislator. The discretionary power of judges is precisely given by the legislators through a blank letter of appointment, prompting them to be able to cope with various new situations and new problems in practice, and to resolve the lack of administrative power and limitations imposed by specific administrative regulations, which results in the abuse of power. Legislation eventually has shortcomings, so the proportionality principle is a powerful weapon in judicial discretion because it provides a legal entrance to judges and uses legal interpretation.

Conflict between Judicial Discretion and Administrative Discretion. The scope of administrative discretion is extended by the principle of proportionality because of the complex realities of society. And there is an objective social basis of discretion. This has led to a further problem brought about by the principle of proportionality, which is a conflict of discretionary power that arises from the contradiction between the judiciary and the executive because of value judgments. "First, modern society has developed rapidly, and the speed of legislation has fallen far short of the pace of social development. Second, modern society has a variety of forms of composition. At the same time, judges must conduct independent analysis and legal use must not be too rigid. Third, the departments enacted by law have only one mandate or purpose, and the implementing agencies should adapt to the judgments of the society at that time. Fourth, the administrative agencies should strengthen relevant experience to adapt to the changing use of modern social laws." Wang Mingyang said. The discretion of the executive authorities should be monitored and reviewed by the judicial authorities to ensure that the balance of power is within the scope of the rule of law. For the judiciary, the functions of the executive should be reduced or even 
exceeded by the judiciary. In order to adjust the ratio between the judiciary and the executive power, the scope of the judicatory review needs to be clarified at this time. The reason is that the administrative and judicial organs are under the rule of law. All have a certain degree of autonomy. When examining an administrative agency, if the judiciary is too strict, it will undermine its independence. Similarly, in the application of justice, the proportionality principle must also take into account this issue. When examining administrative discretionary power, the power of judicial discretion can be in the range of humidity, making the administrative agency have an independent status in the rule of law.

The Danger of Abuse of Discretion. Montesquieu proposed that "all people with power are vulnerable to abuse of power. This is an experience that is not easy forever." It is an axiom of the nature of power. Therefore, administrative power and judicial power are likely to be abused because of imperfect legal constraints. The above points out that the proportionality principle is too abstract and should be attributed to the law of uncertainty. However, starting from its own nature, the principle of proportionality is a general legal principle that restricts administrative power and protects civil rights. It should strive to improve it. In the application of legal principles, judges may make different judgments on different people, subjectivity is extremely strong, and it lies in the fact that they have a wide range of values for judges to judge and measure. Thus, on the basis of the supervisory characteristics of the proportionality principle, the stability and predictability of the law may be adversely affected, because the range and scale of adjustments for different matters may be judged by specific judges based on different events. As a result, this principle has been criticized by German scholar Szide. He believes that there is no clear standard for the principle of proportionality, and that their abuse will lead to subjective and offensive and reasonable consequences and will harm other constitutional concepts such as equality, legal stability and certainty. Judges should not apply the principle of transitional ratios. If they are used improperly, they may even reach the principle of proportionality under the principle of violence.

\section{The Applicable Rules of the Principle of Proportionality: Constraints on Civil Judicial Discretion}

The principle of proportionality between the use of the law indiscriminately may further exacerbate the conflict. At the same time, it will cause judges to abuse power. However, it only embodies the strengthening of control over civil judicial discretion, so it should not be used for food abuse. It prohibits the use of the principle of proportionality in judicial review and the discretion of judges under the principle of proportionality. If you want to use it properly, you should control the judge. Under certain conditions, this article only discusses the following aspects.

Prohibition of Escaping from General Terms. The principle of proportionality in our country as a modern administrative law, has not reached the same conclusion by applying specific provisions and applying general legal principles. At the same time, the law itself has specific provisions. At this time, the principle should not be applied and the specific provisions should be applied. Therefore, in the trial practice, our country's consistent practice does not allow judges to directly quote it as a legal basis. When referring to a specific case, it was interpreted as "prohibition of escaping from general terms". The interpretation rules of this law stipulate that before the implementation of specific laws, they can only be used under certain conditions, that is, in accordance with the existing administrative regulations. If they do not comply with the provisions of the current administrative regulations, the principle of proportionality shall be used as supplementary and supplementary measures. Rights are not fully protected and this reference is applicable. The principle of proportionality can play an important role in the actual imperfect administrative law and proportionality principle in making up for the defects in the application of the current administrative jurisprudence.

Principle of Equal Application. The intrinsic meaning of the proportionality principle is the equal application of law. An ancient Greek philosopher once put forward: "Fairness means proportionality; injustice means destruction." The principle of the proportion of judges' discretionary power, the purpose of making judges free from statutory laws, and the fact that the 
legislator must be treated fairly and fairly in administrative cases that the legislator must deal with in a fair and reasonable manner is considered to be a substantial case-related factor. Increase their values to judge. When examining the same case, it is first and foremost that equality should be brought to the fore, and no distinction can be made between people. This is a complicated process of legal thinking. When the same case appears at different times, the latter should be consistent, that is, the latter should be consistent with the former. If there is inequality in the result of the referee, it means that the law applies to inequality. "The same situation must be handled the same way. Different situations must be treated differently". In the applicable laws, irrespective of race, nationality, beliefs, political parties and other unrelated factors, the fair value judgment is guaranteed to ensure that the legal foundation of the principle of proportionality still exists.

Precedent System Restraint Principle. The development and application of the proportionality principle in specific situations require several levels of interpretation and concretization. This reflects the abstraction of the principle of proportionality. The case law system has its own unique role. Although France is a typical statutory country, it has implemented case law in the field of administrative law. The principle of proportionality has led to some problems caused by judicial discretion. Case law can be used to maintain balance. There are some case laws that follow the system's guarantee of precedent principles. After the long-term accumulation of systems, the principle of reviewing the proportions will tend to be more specific and operational. While developing the principle of proportionality, administrative law is also developing its own system of administrative judgments. The reason is that our country does not have the institutional guarantee of case law, and judges will be difficult to operate and apply. The depth of administrative judicial intervention is hard to grasp. The principle of proportionality is lacking in the case law system. The necessity and possibility of establishing a case law system in China are being studied by scholars in related fields.

The Principle of Judicial Self-discipline. According to the provisions of the law of our country, the discretionary powers of the judiciary and the discretion of the administrative discretion, the rules arising from the principle of proportionality, are the principles of judicial self-regulation. The judiciary has a "final decision power" for reviewing the behavior of the administrative agency. However, the executive authorities have independent discretionary space, and the judiciary should, to some extent, respect its professional judgment and prestige. Therefore, the judge should respect the administrative discretionary power and give the administrative organ a certain range of free judgments. When the applicable ratio is part of the principle of review power should be waived, only specific administrative actions can correct the serious violation of the principle of proportionality and conduct review. In respect of the discretion of administrative discretion and maintenance of administrative efficiency, and for the minor violation of the principle of proportionality, it should not be revoked or changed. The principle of judicial self-regulation should be adhered to when embodying the review criteria of the proportionality principle. The discretion of administrative agencies should not be replaced by administrative agencies, and must not violate the internal regulations and division of labor between the government and the judiciary; When the principle of proportionality is applied, it will require the judge to apply the standard more flexibly, and the court should insist on the accuracy and appropriateness of discretion.

\section{References}

[1] X.J. Zheng: Application and Development of the Principle of Proportionality in Civil Law [J]. Chinese Law, 2016, (2): 152.

[2] H.L. Ji: The Universality of the Principle of Proportionality in Private Law and Its Examples[J]. Political Science and Law Forum, 2016, (3): 95

[3] Y. Li: "On the Proportionality Principle", "Study on Administrative Law," No.2, 2001

[4] Y. Yue: "On the Proportionality Principle in Administrative Law", "Legal Exhibition", No. 9 of 2014

[5] L.S. Bai: "On the Regulation of Proportional Principles to Administrative Law Enforcement", "Legal Exhibition", 2014(11) 
[6] M. Ren: "Applicability of the Proportional Principle under the Administrative Discipline Benchmark", People's Forum, No.17, 2014

[7] J. Cao: "Examining the Application of the Proportional Principle in Administrative Law-A Case of Administrative Inaction by Hemou v. Urban and Rural Planning Bureau", "Legal Exhibition", 2014(8)

${ }^{1}$ Chen Xinmin. Principles of Chinese Administrative Law[M]. Beijing: China University of Political Science and Law Press, 2002. 